\title{
Effectiveness and Safety of Trabeculectomy along with Amniotic Membrane Transplantation on Glaucoma: A Systematic Review
}

\author{
Tian-yi Shen ${ }^{(D)}{ }^{1,2}$ Wei-nan Hu, ${ }^{3}$ Wen-ting Cai ${ }^{1},{ }^{1}$ Hui-zi Jin, ${ }^{1}$ Dong-hui Yu ${ }^{D},{ }^{1}$ \\ Jing-hui Sun $\mathbb{D}^{2},{ }^{2}$ and Jing $Y u \mathbb{D}^{1,2}$ \\ ${ }^{1}$ Department of Ophthalmology, Shanghai Tenth People's Hospital, Tongji University, School of Medicine, \\ Shanghai 200072, China \\ ${ }^{2}$ Ninghai First Hospital, Ninghai, Zhejiang 315600, China \\ ${ }^{3}$ Anhui University of Science and Technology, Huainan, Anhui 232000, China \\ Correspondence should be addressed to Jing-hui Sun; monkeyjump1979@163.com and Jing Yu; dryujing@aliyun.com
}

Received 15 May 2019; Revised 14 March 2020; Accepted 24 March 2020; Published 9 October 2020

Academic Editor: Usha P. Andley

Copyright @ 2020 Tian-yi Shen et al. This is an open access article distributed under the Creative Commons Attribution License, which permits unrestricted use, distribution, and reproduction in any medium, provided the original work is properly cited.

\begin{abstract}
Purpose. To determine the effectiveness and safety of trabeculectomy along with amniotic membrane transplantation (AMT) for glaucoma. Methods. This systematic review was performed using RevMan 5.3. We searched PubMed, EMBASE, and the Cochrane Library and included studies published until September 2019. The treatment group included patients with AMT and trabeculectomy (group A), and the control group had only trabeculectomy (group B). We only included randomized controlled trials. The outcomes were intraocular pressure (IOP), complete success rate, number of antiglaucoma medications, and complications. Results. Five studies, including 174 eyes (87 eyes in the AMT group and 87 eyes in the control group), were eligible in this review. The parameters had no significant difference in heterogeneity between the AMT and control groups preoperatively. In the AMT group, the mean IOP was significantly lower at 3 and 12 months after operation $(P<0.0001$ and $P=0.02$, respectively), while the number of complete successes in the AMT group was significantly higher at 6 and 12 months $(P=0.02$ and $P=0.003$, respectively) compared with the control group. Complications, including a flat anterior chamber and hyphema, appeared to be decreased in the AMT group compared to the control group ( $P=0.02$ and $P=0.02$, respectively). No differences were observed in the number of antiglaucoma medications, hypotony, encapsulated bleb, or choroidal detachment. Conclusion. Compared with only trabeculectomy, it is more efficient and safer to add AMT to trabeculectomy during glaucoma filtering surgery.
\end{abstract}

\section{Introduction}

Glaucoma is a group of progressive optic neuropathies characterized by degeneration of retinal ganglion cells and their axons, resulting in cupping, a distinct appearance of the optic disc, and irreversible visual loss [1,2]. The number of people with open-angle glaucoma (OAG) and angle-closure glaucoma (ACG) will increase to 79.6 million by 2020 worldwide, making it the second leading cause of blindness in the world [3].

The main treatment for glaucoma aims to reduce intraocular pressure (IOP) to slow down the process of vision loss. Medications and laser or incisional surgeries are conventional methods for reducing IOP. Trabeculectomy is the most common incisional surgical procedure, commonly performed in patients with medically uncontrolled glaucoma $[4,5]$. However, postoperative fibrosis that most commonly occurs at the episclera leading to bleb failure months or years after filtering glaucoma surgery has limited the success rate of the treatment $[6,7]$. For fear of these complications, the use of antifibrotic drugs, such as mitomycin-C and 5-fluorouracil, remains the standard for augmented trabeculectomy $[8,9]$. Nonetheless, in some cases, it does not achieve a good filtering effect despite the use of the antifibrotic agents. Besides, endophthalmitis and hypotony may occur [10].

The amniotic membrane (AM) is the innermost layer of the fetal membranes. It is considered to be immunologically 
inert and possesses several physiologic properties, including inhibition of scarring, inflammation, angiogenesis, and provides a substrate for epithelial cell growth and attachment [11]. It is used as a biological tool due to its special structure, biological properties, and immunologic characteristics, which have already been applied in the treatment of burn lesions and for surgical wound covering to avoid collusion [12]. Amniotic membrane transplantation (AMT) has also been widely used in ophthalmic surgery to provide an alternative for corneal and conjunctival reconstruction, including limbal stem cell deficiency, ocular burn, pterygium, tumors, and symblepharon [13-17]. Zhang et al. found that the use of amniotic membranes along with trabeculectomy in primary congenital glaucoma can be an effective surgical method [18].

However, there is a lack of consensus regarding the effectiveness and safety of trabeculectomy with AMT compared with trabeculectomy alone in glaucoma. The objective of this systematic review was to analyze the IOPs and success rate along with complications after these two types of surgery.

\section{Materials and Methods}

2.1. Search Strategy. PubMed, EMBASE, and Cochrane Central Register electronic databases were searched from inception to March 2020, using the key words "glaucoma," "amniotic membrane transplantation," and "trabeculectomy." The search was limited to English language reports without publishing time restriction.

2.2. Inclusion and Exclusion Criteria. Qualified studies included in the study must meet the following criteria: randomized controlled trial (RCT) design without restriction to language or type of publication, participants of all ages with medically uncontrolled glaucoma, use of AMT along with trabeculectomy as a treatment, a trabeculectomy treatment control group, and at least one year of follow-up. Both preoperative and postoperative outcome measures were obtained in each article. Accordingly, variables such as gender, type of glaucoma, and type of amniotic membrane were all potential sources of heterogeneity. Exclusion criteria were as follows: reviews, meetings, letters, animal studies, case reports, non-RCT design, studies without comprehensive data, use of different evaluation outcomes, and some duplicates.

2.3. Data Extraction and Quality Assessment. TY Shen and $\mathrm{WN} \mathrm{Hu}$ independently filtered the titles and abstracts to remove obviously irrelevant reports. TY Shen, WN $\mathrm{Hu}$, and WT Cai examined full-text reports and abstracts to determine the compliance with inclusion criteria. Agreements of detailed evaluation were reached after discussion by three reviewers. The studies which report the similar clinical trials were excluded and reserved one after extraction.

The guidelines in the Cochrane Handbook for Systematic Reviews of Interventions (version 5.1.0, Oxford, UK)

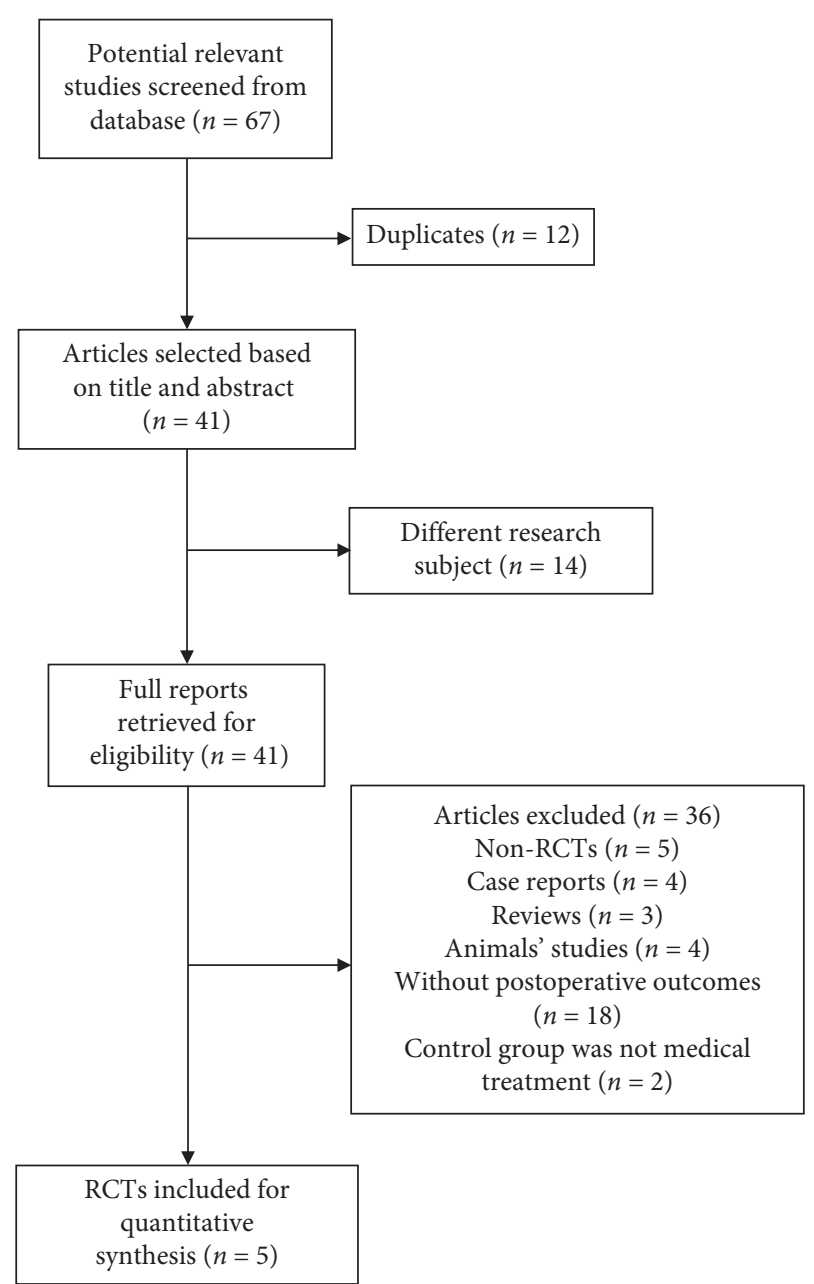

FIGURE 1: Flowchart of search strategy in this systematic review. RCT, randomized controlled clinical trial.

[19] were adopted to validate the quality of all included articles. Data, such as the first author, year, country, randomized counts, age, sex, study design, type of surgery, duration of follow-up, clinical outcomes, and complications, were analyzed. The main clinical outcome was IOP. Secondary outcomes, including complete success rate, number of antiglaucoma medications, and complications, were extracted. Additionally, 12 months was set as the shortest follow-up period.

2.4. Statistical Analysis. RevMan 5.3 was performed for both fixed-effects and random-effects models in this review. To compare outcomes of different groups, odds ratios (ORs) and 95\% confidence intervals (CIs) were used. $P$ values were considered to be statistically significant at less than 0.05 level. Heterogeneity was evaluated with an $I^{2}$ test in which more than $50 \%$ was considered to be significant. If significant heterogeneity was observed $(P \leq 0.05)$, a random-effects model was used for analyzing the data; otherwise, a fixed-effects model was performed $(P>0.05)$. Forest plot was estimated to show the comparison clearly $[20,21]$. 
TABLE 1: Patient characteristics in the included trials.

\begin{tabular}{|c|c|c|c|c|c|c|c|c|c|}
\hline Reference & Year & Location & Inclusion criteria & Intervention & Eyes & $\begin{array}{c}\text { Age, year } \\
(\text { mean } \pm S D)\end{array}$ & $\operatorname{Sex}(M / F)$ & $\begin{array}{l}\text { Follow-up } \\
\text { time (mos) }\end{array}$ & Outcomes \\
\hline $\begin{array}{l}\text { Sheha } \\
\text { et al. [22] }\end{array}$ & 2008 & Germany & $\begin{array}{l}\text { Refractory } \\
\text { glaucoma }\end{array}$ & $\begin{array}{l}\text { Trabeculectomy } \\
\text { with AMT }\end{array}$ & 19 & $57.6 \pm 6.3$ & $13 / 6$ & 12 & $\begin{array}{l}\text { Mean IOPs; success } \\
\text { rate; mean number } \\
\text { of antiglaucoma } \\
\text { medications; } \\
\text { complications }\end{array}$ \\
\hline $\begin{array}{l}\text { Mahdy } \\
\text { et al. [23] }\end{array}$ & 2010 & Egypt & $\begin{array}{l}\text { Primary pediatric } \\
\text { glaucoma }\end{array}$ & $\begin{array}{c}\text { Trabeculectomy } \\
\text { Trabeculectomy } \\
\text { with AMT }\end{array}$ & $\begin{array}{l}15 \\
15\end{array}$ & $\begin{array}{l}6 \pm 2.1 \\
6 \pm 1.8\end{array}$ & $\begin{array}{l}7 / 6 \\
5 / 7\end{array}$ & 18 & $\begin{array}{l}\text { Mean IOPs; success } \\
\text { rate; complications }\end{array}$ \\
\hline $\begin{array}{l}\text { Yadava } \\
\text { et al. [24] }\end{array}$ & 2017 & India & POAG; PACG & $\begin{array}{l}\text { Trabeculectomy } \\
\text { Trabeculectomy } \\
\text { with AMT }\end{array}$ & $\begin{array}{l}20 \\
20\end{array}$ & $\begin{array}{c}54.65 \pm 11.05 \\
50.95 \pm 9.54\end{array}$ & $\begin{array}{l}11 / 9 \\
9 / 11\end{array}$ & 12 & $\begin{array}{l}\text { Mean IOPs; success } \\
\text { rate; complications }\end{array}$ \\
\hline $\begin{array}{l}\text { Eliezer } \\
\text { et al. [25] }\end{array}$ & 2006 & Brazil & POAG & $\begin{array}{l}\text { Trabeculectomy } \\
\text { with AMT }\end{array}$ & 16 & $68.3 \pm 13.6$ & $11 / 5$ & 12 & $\begin{array}{l}\text { Mean IOPs; BCVA; } \\
\text { mean number of } \\
\text { antiglaucoma } \\
\text { medications; } \\
\text { complications }\end{array}$ \\
\hline $\begin{array}{l}\text { Ji et al. } \\
\text { [26] }\end{array}$ & 2013 & China & $\begin{array}{l}\text { Chronic angle- } \\
\text { closure glaucoma; } \\
\text { POAG }\end{array}$ & $\begin{array}{c}\text { Trabeculectomy } \\
\text { Trabeculectomy } \\
\text { with AMT }\end{array}$ & $\begin{array}{l}17 \\
17\end{array}$ & $61.6 \pm 13.4$ & $10 / 7$ & 24 & $\begin{array}{l}\text { Mean IOPs; success } \\
\text { rate; complications }\end{array}$ \\
\hline
\end{tabular}

POAG, primary open-angle glaucoma; PAGC: primary angle-closure glaucoma; AMT: amniotic membrane transplantation

\section{Results}

3.1. Literature Search. A total of 67 articles were identified by the original literature search (Figure 1), including $12 \mathrm{du}-$ plications. Reviewing the titles and abstracts, 41 articles were identified to be eligible for the full text of articles. Furthermore, 36 articles were excluded for the following reasons: non-RCTs, 5; case reports, 4; reviews, 3; animal studies, 4; without detailed outcomes, 18; and control group did not have trabeculectomy treatment, 2 . As a result, 5 papers were available. Figure 1 is the flowchart of the literature retrieval progress.

3.2. Description. Table 1 shows the characteristics of the five trials. All of the studies included were RCTs. Totally, 174 eyes of 151 participants were identified with the size of the population ranging from 30 to 40 , comprising $85(56.3 \%)$ males and $66(43.7 \%)$ females. The control group contained 87 patients as did the study group. Participants included all ages. The follow-up period ranged from 12 to 24 months, the minimum being 12 months. We used blinded fashion to assess the studies. Studies from Egypt, Germany, India, Brazil, and China were included.

3.3. Quality Assessment. We used the bias assessment tool, which was recommended by the Cochrane Collaboration for RCTs. Figure 2 shows the quality of the included studies. Though all the eligible studies indicated the use of randomized controlled trials, only two of them clearly listed the random block permutation method. Sensitivity analysis showed no statistically significant differences by removing individual trial. Funnel plots were not used to assess publication bias as fewer than ten trials were available.

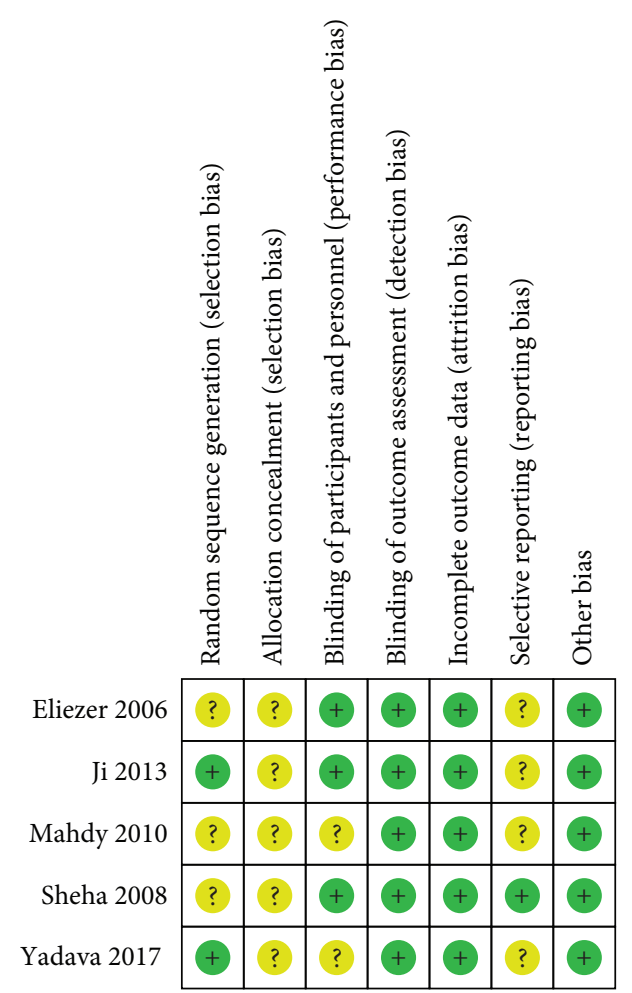

FIgURE 2: Methodological quality summary: authors' judgments about each methodological quality item for each included study. Note: + represents yes; ? represents unclear.

\subsection{Primary Outcome}

3.4.1. Mean IOPs. As shown in Figure 3, the mean IOPs decreased in both the trabeculectomy with AMT group (group A) and the trabeculectomy-alone group (group B). Before surgery, no difference appeared between two groups 


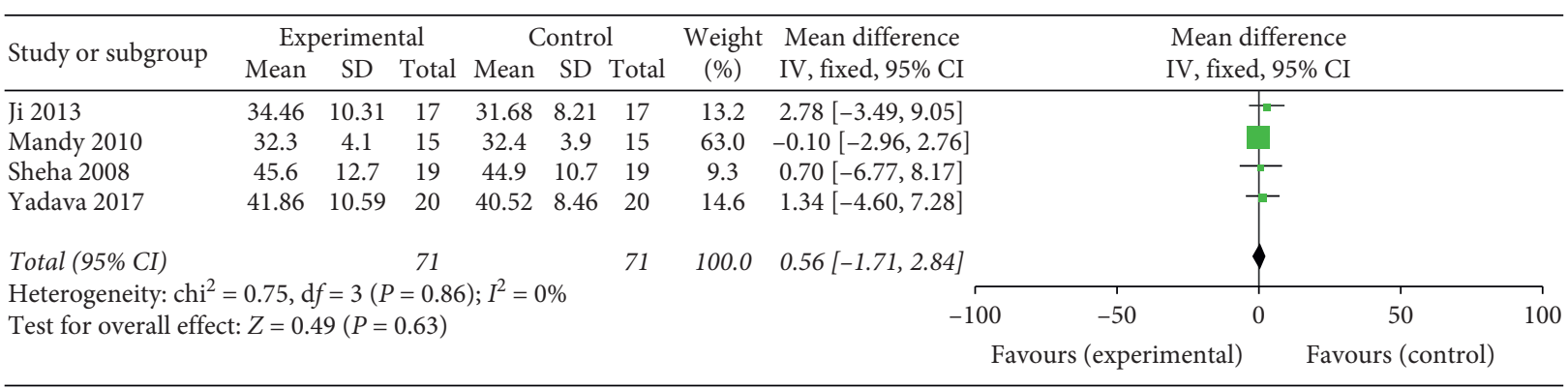

(a)

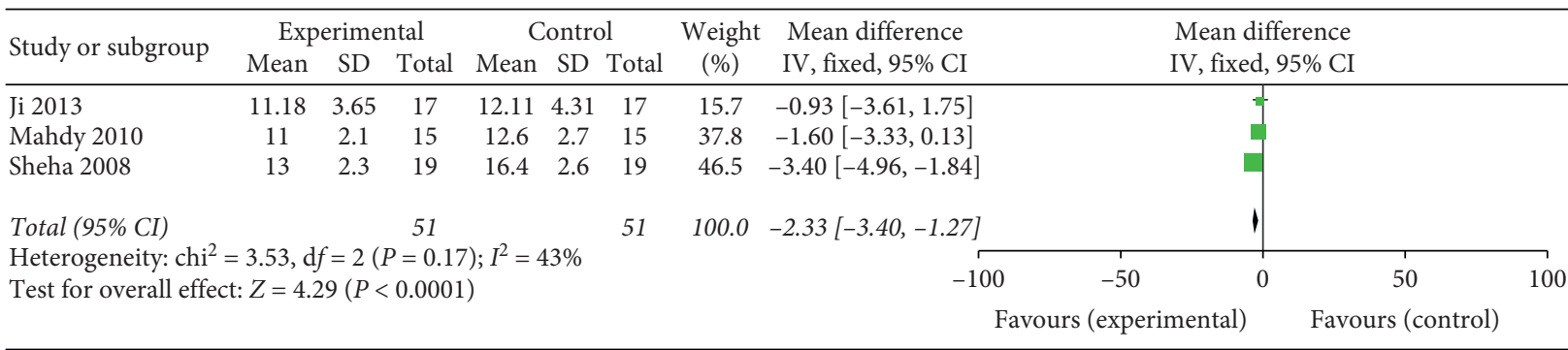

(b)

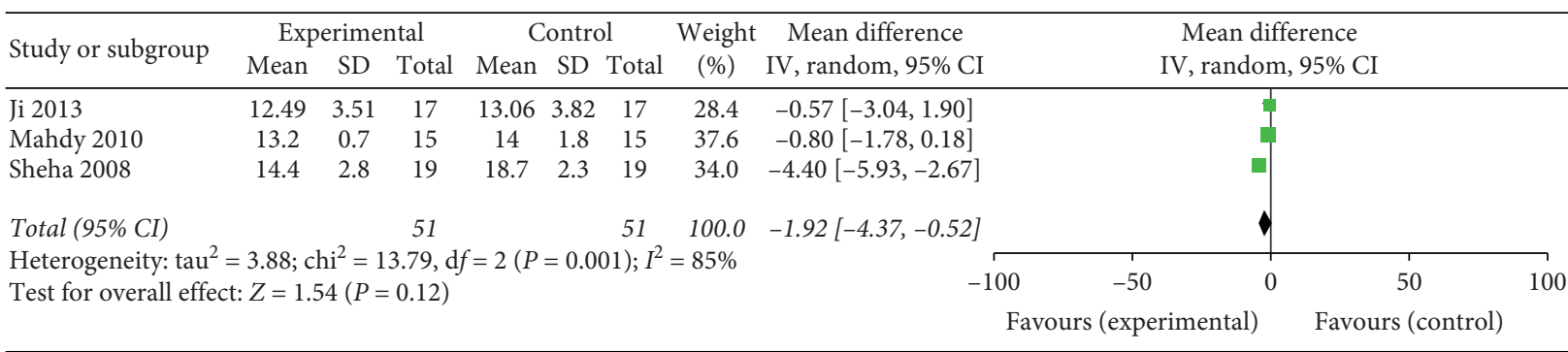

(c)

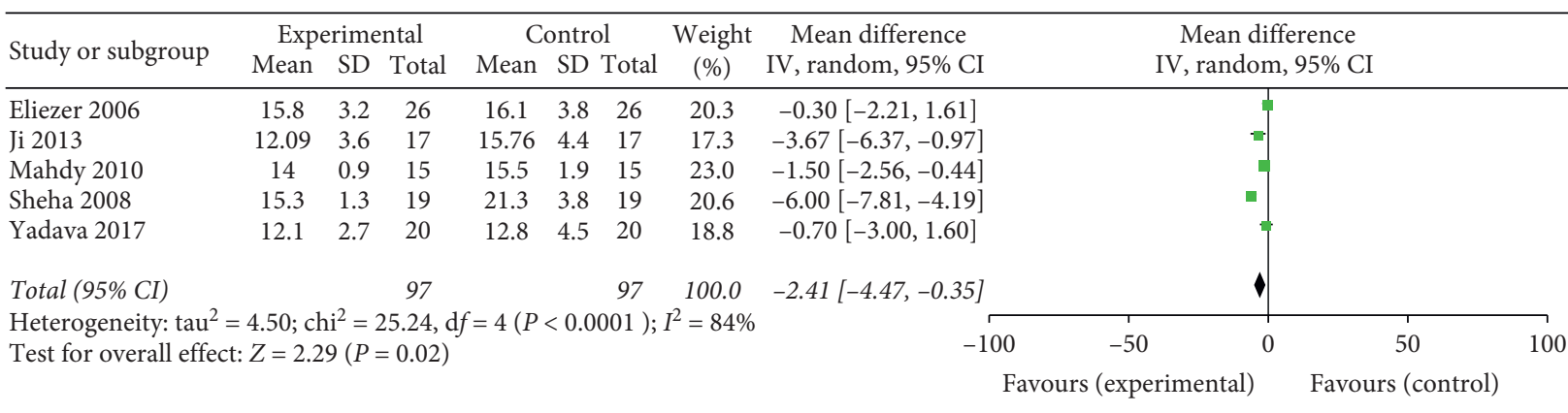

(d)

FIGURE 3: Forest plot comparison of IOP after treatment in the AMT and control group (a) preoperatively, (b) three months postoperatively, (c) six months postoperatively, and (d) one year postoperatively.

(WMD: $0.56,95 \% \mathrm{CI}:-1.71$ to 2.84 , and $P=0.63$ ) (Figure 3(a)). At three months (WMD: -2.33 , 95\% CI: -3.40 to -1.27 , and $P \leq 0.0001$ ) (Figure $3(\mathrm{~b})$ ) and twelve months (WMD: $-2.41,95 \% \mathrm{CI}:-4.47$ to -0.35 , and $P=0.02$ ) (Figure 3(d)) after the treatment, the level of the mean IOP in group A was significantly lower than that in group B, while the mean IOP showed no difference at six months (WMD: $-1.92,95 \% \mathrm{CI}:-4.37$ to 0.52 , and $P=0.12$ ) (Figure 3(c)).

\subsection{Secondary Outcomes}

3.5.1. The Number of Eyes with Complete Success. There were four studies reporting the number of completely successful eyes after surgery at different time points. The number of successes shows significant improvement at six (OR: 4.46, 95\% CI: 1.23 to 16.09 , and $P=0.02$ ) and twelve months (OR: 4.79, 95\% CI: 1.68 to 13.65 , and $P=0.003$ ) after operation (Figure 4). 


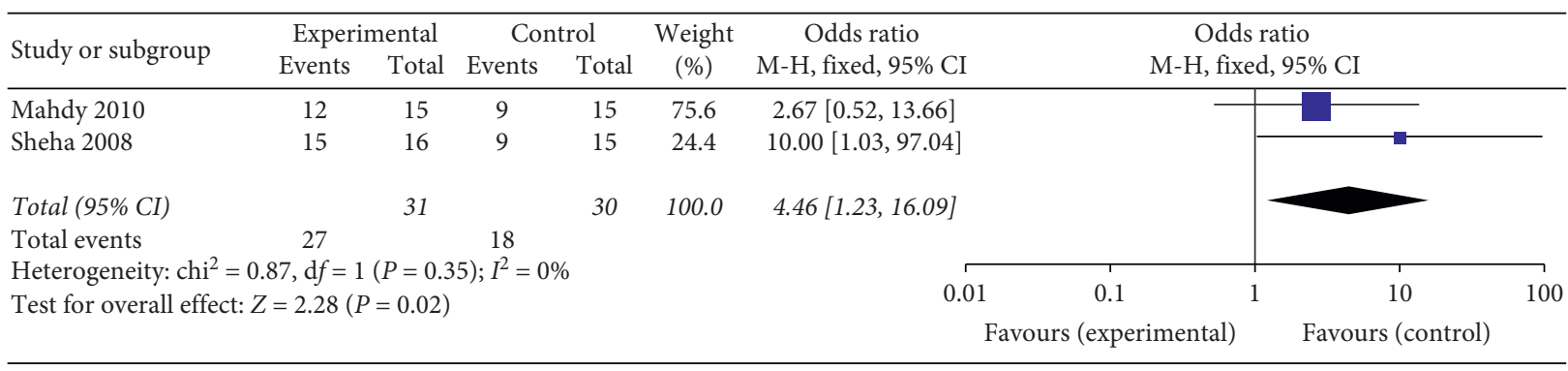

(a)

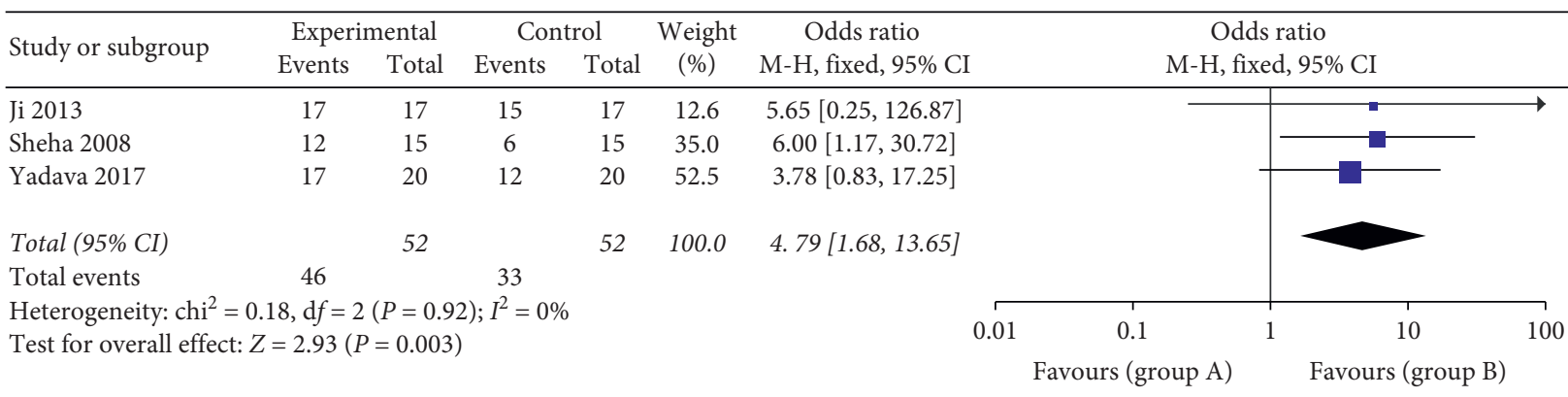

(b)

Figure 4: Forest plot comparison of the number of eyes with complete success after treatment in AMT and control group. (a) Six months postoperatively; (b) One year postoperatively.

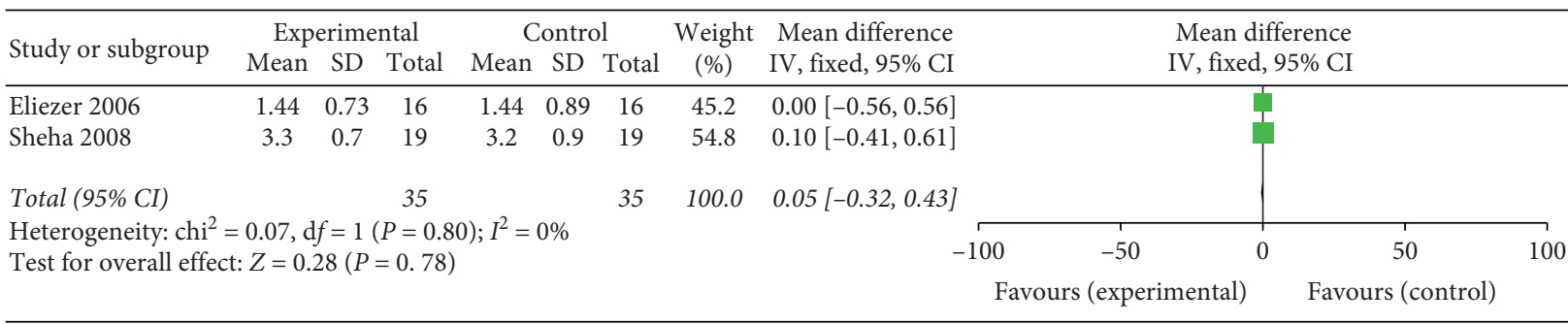

(a)

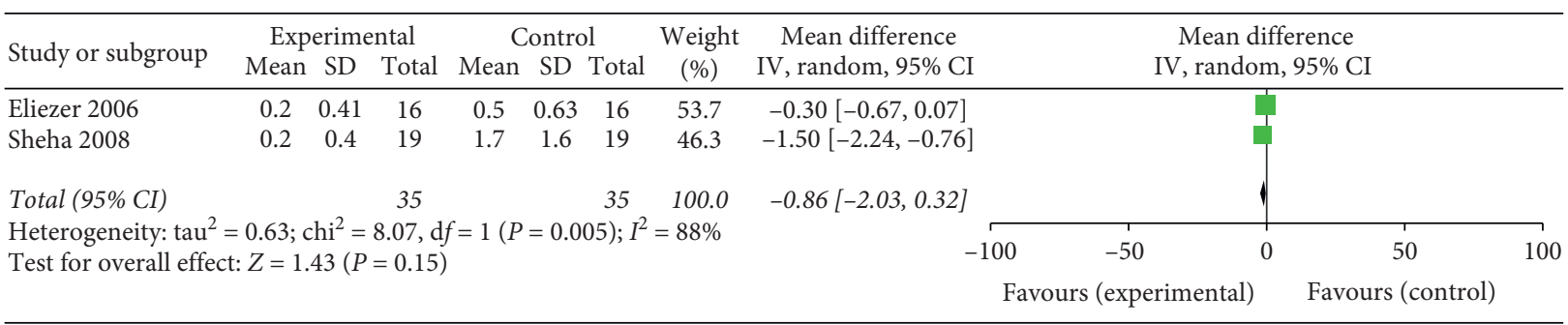

(b)

Figure 5: Forest plot comparison of the number of antiglaucoma medications after treatment in the AMT and control group (a) preoperatively and (b) one year postoperatively.

3.5.2. The Number of Antiglaucoma Medications. Two articles included the number of antiglaucoma medications before and after surgery. The difference between the two groups was not significant both before (WMD: 0.05, 95\% CI: -0.32 to 0.43 , and $P=0.78$ ) and after the surgery (WMD: $-0.86,95 \% \mathrm{CI}:-2.03$ to 0.32 , and $P=0.15$ ) (Figure 5).
3.5.3. Complications. The complication rates of hypotony, flat anterior chamber, hyphema, encapsulated bleb, and choroidal detachment were assessed after operation. A flat anterior chamber (OR: $0.24,95 \% \mathrm{CI}: 0.07$ to 0.82 , and $P=0.02$ ) (Figure 6(b)) and hyphema (OR: 0.21, 95\% CI: 0.06 to 0.76 , and $P=0.02$ ) (Figure $6(\mathrm{c})$ ) appeared significantly 


\begin{tabular}{|c|c|c|c|c|c|c|c|c|c|}
\hline \multirow{2}{*}{ Study or subgroup } & \multicolumn{2}{|c|}{ Experimental } & \multicolumn{2}{|c|}{ Control } & \multirow{2}{*}{$\begin{array}{l}\text { Weight } \\
(\%)\end{array}$} & \multirow{2}{*}{$\begin{array}{c}\text { Odds ratio } \\
\text { M-H, fixed, } 95 \% \text { CI }\end{array}$} & \multirow{2}{*}{\multicolumn{3}{|c|}{$\begin{array}{c}\text { Odds ratio } \\
\text { M-H, fixed, } 95 \% \text { CI }\end{array}$}} \\
\hline & Events & Total & Events & Total & & & & & \\
\hline Mahdy 2010 & 0 & 15 & 2 & 15 & 41.5 & $0.17[0.01,3.96]$ & & & \\
\hline Sheha 2008 & 0 & 19 & 3 & 19 & 58.5 & $0.12[0.01,2.51]$ & & & \\
\hline \multicolumn{2}{|c|}{ Total $(95 \%$ CI) } & 34 & & 34 & 100.0 & $0.14[0.02,1.25]$ & & & \\
\hline \multirow{2}{*}{\multicolumn{5}{|c|}{$\begin{array}{l}\text { Total events } \quad 0 \\
\text { Heterogeneity: chi }{ }^{2}=0.03, \mathrm{~d} f=1(P=0.87) ; I^{2}=0 \% \\
\text { Test for overall effect: } Z=1.76(P=0.08)\end{array}$}} & & & & & \\
\hline & & & & & & & $0.01 \quad 0.1$ & 10 & 100 \\
\hline & & & & & & & Favours (experimental) & Favours (control) & \\
\hline
\end{tabular}

(a)

\begin{tabular}{|c|c|c|c|c|c|c|c|c|c|}
\hline \multirow{2}{*}{ Study or subgroup } & \multicolumn{2}{|c|}{ Experimental } & \multicolumn{2}{|c|}{ Control } & \multirow{2}{*}{$\begin{array}{l}\text { Weight } \\
(\%)\end{array}$} & \multirow{2}{*}{$\begin{array}{c}\text { Odds ratio } \\
\mathrm{M}-\mathrm{H} \text {, fixed, } 95 \% \mathrm{CI} \\
\end{array}$} & \multirow{2}{*}{\multicolumn{2}{|c|}{$\begin{array}{c}\text { Odds ratio } \\
\text { M-H, fixed, } 95 \% \text { CI }\end{array}$}} & \\
\hline & Events & Total & Events & Total & & & & & \\
\hline Ji 2013 & 1 & 17 & 3 & 17 & 24.9 & $0.29[0.03,3.13]$ & $\rightarrow$ & & \\
\hline Mahdy 2010 & 2 & 15 & 7 & 15 & 53.6 & $0.18[0.03,1.07]$ & & & \\
\hline Sheha 2008 & 0 & 19 & 2 & 19 & 21.5 & $0.18[0.01,4.00]$ & & & \\
\hline Total (95\% CI) & & 51 & & 51 & 100.0 & $0.21[0.06,0.76]$ & & & \\
\hline \multirow{3}{*}{\multicolumn{7}{|c|}{$\begin{array}{l}\text { Total events } \quad 3 \\
\text { Heterogeneity: chi }{ }^{2}=0.12, \mathrm{~d} f=2(P=0.94) ; I^{2}=0 \% \\
\text { Test for overall effect: } Z=2.38(P=0.02)\end{array}$}} & & & \\
\hline & & & & & & & $\begin{array}{lll}.01 & 0.1\end{array}$ & 10 & \\
\hline & & & & & & & Favours (experimental) & Favours (control) & \\
\hline
\end{tabular}

(b)

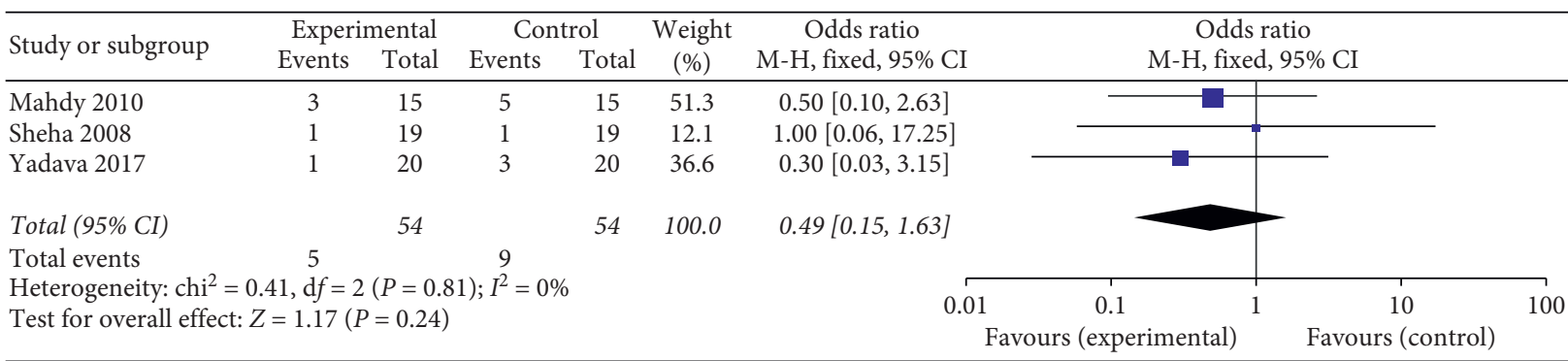

(c)

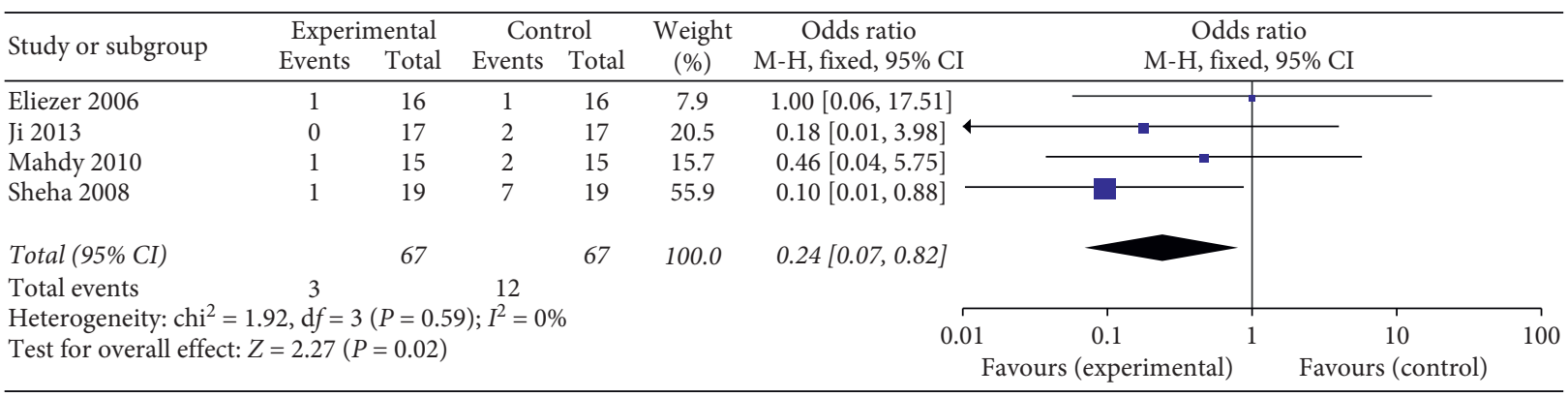

(d)

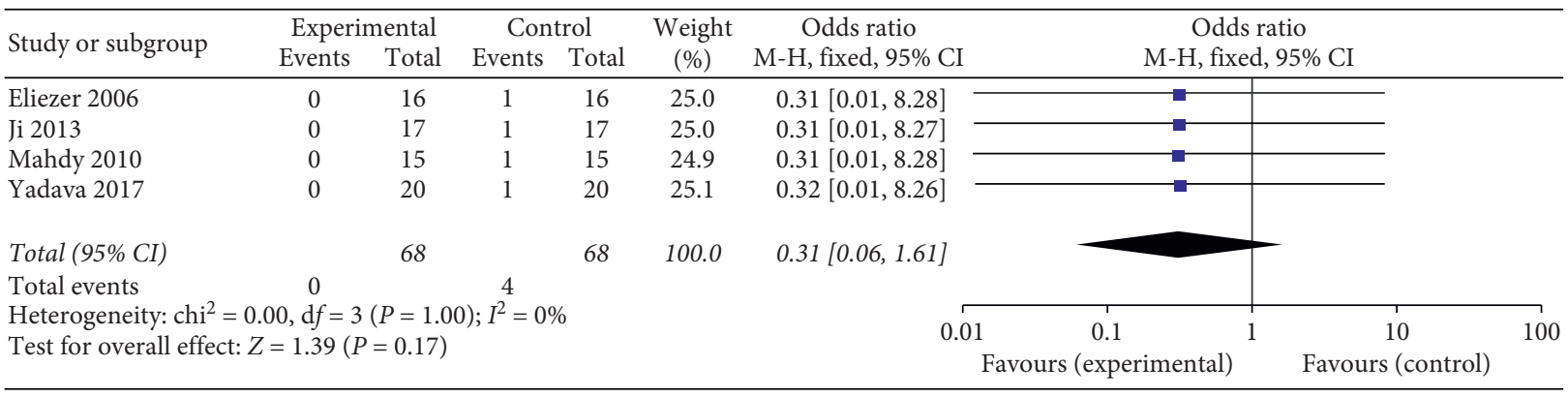

(e)

FIGURE 6: Forest plot comparison of complications after treatment in the AMT and control group. (a) Hypotony. (b) Flat anterior chamber. (c) Hyphema. (d) Encapsulated bleb. (e) Choroidal detachment. 
decreased in group A compared with group B, while hypotony (OR: 0.31 , 95\% CI: 0.06 to $1.61, P=0.17$ ) (Figure 6(a)), encapsulated bleb (OR: 0.49, 95\% CI: 0.15 to 1.63, $P=0.24$ ) (Figure 6(d)), and choroidal detachment (OR: 0.14, 95\% CI: 0.02 to $1.25, P=0.08$ ) (Figure $6(\mathrm{e})$ ) showed no difference.

3.6. Heterogeneity. Heterogeneity appeared in some of the outcomes. This systematic review included all ages with glaucoma, of which Mahdy et al. [23] assessed the children with glaucoma. After excluding primary pediatric glaucoma, the analysis showed similar results as previous. The outcome indicated that our conclusions remained stable.

\section{Discussion}

Trabeculectomy has been widely used as the traditional filtering surgery to control IOP levels with antiglaucoma medications alone in glaucoma. However, the complications of fibrosis, which may affect visual function, made a permanent result difficult.

Due to the limitations mentioned above, AM became an adjuvant treatment. It has been shown to inhibit squamous metaplasia of the conjunctival epithelium, suppress inflammation and neovascularization, promote limbal stem cell expansion, and accelerate the corneal epithelium [27-29]. The AMT pathway may downregulate transforming growth factor- $\beta$ signaling in cultured normal conjunctival and pterygium fibroblasts [30]. Moreover, amniotic membrane proteins can modulate the gene involved in apoptosis and reduce oxidative stress along with inflammatory responses in a hypoxic condition [31].

As the main target of glaucoma, elevated IOP is associated with glaucomatous optic nerve damage and visual field loss. Kimball et al. [32] found that IOP elevation in elder mice caused clear abnormalities in the density and movement of mitochondria as well as axonal integrity. The stability of IOP seems to be essential. Shao et al. [33] has proven the effectiveness of adding AMT to trabeculectomy, resulting in a controlled IOP and a functional filtration bleb sustained in rabbit glaucoma models, which were the same as the statistics shown in this review. IOP levels decreased to normal after treatment in the two groups, while the decline in the AMT group was more notable and stable. We came to the conclusion that trabeculectomy with AMT shows superiority in reducing IOP levels compared to trabeculectomy alone. At the same time, it produces a complete success rate at a high standard. We excluded qualified successes (having an IOP of $21 \mathrm{~mm} \mathrm{Hg}$ or less with or without antiglaucoma medications) so that more valuable statistics could be acquired. Although the number of antiglaucoma medications was equal before and after surgery, the complete success rate can indicate an advantage in the AMT group.

Complications are a long-term index that can be used to qualify surgeries. Five kinds of complications, including hypotony, flat anterior chamber, hyphema, encapsulated bleb, and choroidal detachment were analyzed. Hypotony, flat anterior chamber, and choroidal detachment had a low probability when AM was inserted under the scleral flap, and they halted rapid drainage of the aqueous humor from the trabeculectomy site effectively, [22] though only cases of a flat anterior chamber had a significant decrease in the AMT group. Hyphema, the accumulation of blood in the anterior chamber, [34] can be seen after ocular trauma, intraocular surgery, or spontaneously, which can cause complications such as secondary hemorrhage and glaucoma [35]. On the basis of review, the AMT group was able to avoid this complication, which may reduce the recurrence of glaucoma. Collagen-producing fibroblasts are always the reason for encapsulated blebs, which may elevate IOP, leading the eye to be uncomfortable from the effects of a localized dellen [36]. The AMT group had a lower prevalence of fibroblasts than the control group, though without significance.

In conclusion, although only prospective studies were included, some limitations should not be overlooked. First, not every article explained the randomized strategy explicitly and convincingly. Second, some factors, such as the size of glaucoma, treatment before operation, surgeon skills, and surgical methods, could have affected our results. Third, for lack of an abundant number of eligible cases, some statistics were unable to be acquired, and a limitation exists regarding visual ability and other vision aspects. Overall, this review suggested that AMT is an effective and safe treatment in combination with trabeculectomy in glaucoma for its stable IOP level, high success rate, and low incidence rate of complications.

\section{Data Availability}

The data used to support the findings of this study are included within the article.

\section{Conflicts of Interest}

The authors declare that they have no conflicts of interest.

\section{Authors' Contributions}

All authors contributed to data analysis, drafting, and revising the paper and agreed to be accountable for all aspects of the work. Tian-yi Shen and Wei-nan $\mathrm{Hu}$ contributed equally to this work.

\section{Acknowledgments}

This work was supported by the Fundamental Research Funds for the Central Universities in 2018 (project number: PA2018001057), Shanghai, China.

\section{References}

[1] R. N. Weinreb and P. T. Khaw, "Primary open-angle glaucoma," The Lancet, vol. 363, no. 9422, pp. 1711-1720, 2004.

[2] R. N. Weinreb, T. Aung, and F. A. Medeiros, "The pathophysiology and treatment of glaucoma," JAMA, vol. 311, no. 18, pp. 1901-1911, 2014.

[3] H. A. Quigley and A. T. Broman, "The number of people with glaucoma worldwide in 2010 and 2020," British Journal of Ophthalmology, vol. 90, no. 3, pp. 262-267, 2006. 
[4] X. Wang, R. Khan, and A. Coleman, "Device-modified trabeculectomy for glaucoma," The Cochrane Database of Systematic Reviews, vol. 12, no. 12, Article ID CD010472, 2015.

[5] V. L. Tseng, C. H. Kim, P. T. Romero et al., "Risk factors and long-term outcomes in patients with low intraocular pressure after trabeculectomy," Ophthalmology, vol. 124, no. 10, pp. 1457-1465, 2017.

[6] É. Csősz, N. Tóth, E. Deák, A. Csutak, and J. Tőzsér, "WoundHealing markers revealed by proximity extension assay in tears of patients following glaucoma surgery," International Journal of Molecular Sciences, vol. 19, no. 12, Article ID E4096, 2018.

[7] F. Bochmann and A. Azuara-Blanco, "Interventions for late trabeculectomy bleb leak," The Cochrane Database of Systematic Reviews, vol. 12, no. 9, Article ID CD006769, 2012.

[8] C. Zhang, M. Wu, J. Wang et al., "Use of 5-fluorouracilsoaked bioamniotic membranes in trabeculectomy for primary open-angle glaucoma: a retrospective analysis," Journal of Ophthalmology, vol. 2017, Article ID 2698975, 6 pages, 2017.

[9] D. Mittal, M. Bhoot, and S. Dubey, "Trabeculectomy with mitomycin-C," Journal of Glaucoma, vol. 27, no. 11, Article ID e186, 2018.

[10] W. Kiddee, L. Orapiriyakul, K. Kittigoonpaisan, T. Tantisarasart, and B. Wangsupadilok, "Efficacy of adjunctive subconjunctival bevacizumab on the outcomes of primary trabeculectomy with mitomycin C," Journal of Glaucoma, vol. 24, no. 8, pp. 600-606, 2015.

[11] J. A. P. Gomes, A. Romano, M. S. Santos, and H. S. Dua, "Amniotic membrane use in ophthalmology," Current Opinion in Ophthalmology, vol. 16, no. 4, pp. 233-240, 2005.

[12] C. L. Insausti, A. Alcaraz, E. M. García-Vizcaíno et al., "Amniotic membrane induces epithelialization in massive posttraumatic wounds," Wound Repair and Regeneration, vol. 18, no. 4, pp. 368-377, 2010.

[13] T. P. Utheim, Ø. A. Utheim, P. Salvanos et al., "Concise review: altered versus unaltered amniotic membrane as a substrate for limbal epithelial cells," Stem Cells Translational Medicine, vol. 7, no. 5, pp. 415-427, 2018.

[14] A. Tamhane, N. R. Vajpayee, R. M. Pandey, N. Sharma, J. S. Titiyal, and R. Tandon, "Evaluation of amniotic membrane transplantation as an adjunct to medical therapy as compared with medical therapy alone in acute ocular burns," Ophthalmology, vol. 112, no. 11, pp. 1963-1969, 2005.

[15] X. Pan, D. Zhang, Z. Jia et al., "Comparison of hyperdry amniotic membrane transplantation and conjunctival autografting for primary pterygium," BMC Ophthalmology, vol. 18, no. 1, p. 119, 2018.

[16] M. Palamar, B. Yaman, T. Akalın, and A. Yağc1, “Amniotic membrane transplantation in surgical treatment of conjunctival melanoma: long-term results," Türk Oftalmoloji Dergisi, vol. 48, no. 1, pp. 15-18, 2018.

[17] S. Naxer, M. Horn, and M. Schittkowski, "Processed amniotic membrane for conjunctival reconstruction in complex strabismus surgery," Strabismus, vol. 26, no. 4, pp. 191-197, 2018.

[18] C. Zhang, J. Wang, H. Gao et al., "Retrospective observation on trabeculectomy of primary congenital glaucoma by applying biological amniotic membranes soaked with 5-fluorouracil," International Ophthalmology, vol. 38, no. 5, pp. 1933-1940, 2018.

[19] D. Moher, D. J. Cook, A. R. Jadad et al., "Assessing the quality of reports of randomised trials: implications for the conduct of meta-analyses," Health Technol Assess, vol. 3, no. 12, pp. 1-98, 1999.
[20] C. B. Begg and M. Mazumdar, "Operating characteristics of a rank correlation test for publication bias," Biometrics, vol. 50, no. 4, pp. 1088-1101, 1994.

[21] J. Kovačić and V. M. Varnai, "A graphical model approach to systematically missing data in meta-analysis of observational studies," Statistics in Medicine, vol. 35, no. 24, pp. 4443-4458, 2016.

[22] H. Sheha, A. Kheirkhah, and H. Taha, "Amniotic membrane transplantation in trabeculectomy with mitomycin $\mathrm{C}$ for refractory glaucoma," Journal of Glaucoma, vol. 17, no. 4, pp. 303-307, 2008.

[23] R. A. Mahdy, W. M. Nada, S. M. Almasalamy, H. A. Anany, and A. M. Almasary, "A freeze-dried (lyophilized) amniotic membrane transplantation with mitomycin $\mathrm{C}$ and trabeculectomy for pediatric glaucoma," Cutaneous and Ocular Toxicology, vol. 29, no. 3, pp. 164-170, 2010.

[24] U. Yadava, K. Jaisingh, S. Dangda, P. Thacker, K. Singh, and Y. Goel, "Simultaneous use of amniotic membrane and Mitomycin C in trabeculectomy for primary glaucoma," Indian Journal of Ophthalmology, vol. 65, no. 11, pp. 1151-1155, 2017.

[25] R. N. Eliezer, N. Kasahara, C. Caixeta-Umbelino, R. K. Pinheiro, C. Mandia Junior, and R. F. S. Malta, "Use of amniotic membrane in trabeculectomy for the treatment of glaucoma: a pilot study," Arquivos Brasileiros de Oftalmologia, vol. 69, no. 3, pp. 309-312, 2006.

[26] Q. S. Ji, B. Qi, L. Liu et al., "Comparison of trabeculectomy and trabeculectomy with amniotic membrane transplantation in the same patient with bilateral glaucoma," International Journal of Ophthalmology, vol. 6, no. 4, pp. 448-451, 2013.

[27] Y. Tan, F. Qiu, Y.-L. Qu et al., "Amniotic membrane inhibits squamous metaplasia of human conjunctival epithelium," American Journal of Physiology-Cell Physiology, vol. 301, no. 1, pp. C115-C125, 2011.

[28] G. S. Figueiredo, S. Bojic, P. Rooney et al., "Gamma-irradiated human amniotic membrane decellularised with sodium dodecyl sulfate is a more efficient substrate for the ex vivo expansion of limbal stem cells," Acta Biomaterialia, vol. 61, pp. 124-133, 2017.

[29] N. Shayan Asl, F. Nejat, P. Mohammadi et al., "Amniotic membrane extract eye drop promotes limbal stem cell proliferation and corneal epithelium healing," Cell Journal, vol. 20, no. 4, pp. 459-468, 2019.

[30] S. C. G. Tseng, D.-Q. Li, and X. Ma, "Suppression of transforming growth factor-beta isoforms, TGF- $\beta$ receptor type II, and myofibroblast differentiation in cultured human corneal and limbal fibroblasts by amniotic membrane matrix," Journal of Cellular Physiology, vol. 179, no. 3, pp. 325-335, 1999.

[31] Y. Faridvand, S. Nozari, S. Atashkhoei, M. Nouri, and A. Jodati, "Amniotic membrane extracted proteins protect H9c2 cardiomyoblasts against hypoxia-induced apoptosis by modulating oxidative stress," Biochemical and Biophysical Research Communications, vol. 503, no. 3, pp. 1335-1341, 2018.

[32] E. C. Kimball, J. L. Jefferys, M. E. Pease et al., "The effects of age on mitochondria, axonal transport, and axonal degeneration after chronic IOP elevation using a murine ocular explant model," Experimental Eye Research, vol. 172, pp. 78-85, 2018.

[33] Y. Shao, Y. Yu, Q. P. Liu et al., "Effects of Honghua preserved amniotic membrane on scar healing in experimental glaucoma surgery," International Journal of Ophthalmology, vol. 7, no. 2, pp. 226-231, 2014.

[34] A. Gharaibeh, H. I. Savage, R. W. Scherer, M. F. Goldberg, and K. Lindsley, "Medical interventions for traumatic hyphema," 
The Cochrane Database of Systematic Reviews, vol. 1, Article ID CD005431, 2019.

[35] S. Bansal, D. V. Gunasekeran, B. Ang et al., "Controversies in the pathophysiology and management of hyphema," Survey of Ophthalmology, vol. 61, no. 3, pp. 297-308, 2016.

[36] P. Laspas, P. D. Culmann, F. H. Grus et al., "A new method for revision of encapsulated blebs after trabeculectomy: combination of standard bleb needling with transconjunctival scleral flap sutures prevents early postoperative hypotony," PLoS One, vol. 11, no. 6, Article ID e0157320, 2016. 